\title{
APPROXIMATE FUNCTION FOR UNSTEADY AERODYNAMIC KERNEL FUNCTION OF AEROELASTIC LIFTING SURFACES
}

\author{
Erwin Sulaeman And Layeeq AhMed \\ Department of Mechanical Engineering, Faculty of Engineering, \\ International Islamic University Malaysia, \\ PO Box 10, 50728, Kuala Lumpur, Malaysia. \\ esulaeman@iium.edu.my
}

\begin{abstract}
Prediction of unsteady aerodynamic loads is still the most challenging tasks in flutter aeroelastic analysis. Generally, the numerical estimation of steady and unsteady aerodynamics of thin lifting surface is conducted based on an integral equation relating aerodynamic pressure and normal wash velocity. The present work attempts to increase the accuracy of the prediction by using an approximate approach to evaluate kernel function occurring in the integral equation in the form of cylindrical function. Following previous approximation approaches by other researchers to solve the cylindrical function for planar lifting surfaces, this paper extends such approaches to non planar lifting surfaces. To increase the accuracy of the method, the integration region of the kernel function is divided into two parts - near and far regions, where a nonlinear regression curve fitting technique is adapted to estimate the denominator part of the cylindrical function of each region.
\end{abstract}

ABSTRAK: Penelahan daya aerodinamik tidak stabil merupakan satu tugas yang mencabar dalam menganalisis getaran aeroanjalan. Umumnya, anggaran berangka untuk daya aerodinamik stabil dan tidak stabil pada permukaan mengangkat yang nipis, adalah berdasarkan kepada persamaan kamiran di antara tekanan aerodinamik dan halaju aliran udara pada garis normal yang terhasil di bawah sayap pesawat. Kajian ini adalah bertujuan untuk menghasilkan penelahan daya aerodinamik yang lebih tepat dengan menggunakan pendekatan kira hampir untuk menilai fungsi Kernel yang terdapat dalam persamaan kamiran dalam bentuk fungsi silinder. Dengan menggunakan pendekatan kira hampir yang digunakan oleh penyelidik sebelumnya untuk menyelesaikan fungsi silinder pada permukaan mengangkat satah, kajian ini mengembangkan pendekatan tersebut kepada permukaan mengangkat tak sesatah. Untuk meningkatkan lagi ketepatan penelahan, kawasan pengamiran fungsi Kernel dibahagikan kepada dua bahagian, kawasan hampir dan kawasan jauh, di mana penyuaian lengkung regresi tak linear digunakan untuk kiraan hampir penyebut pada fungsi silinder pada setiap kawasan.

KEYWORDS: aeroelasticity; unsteady aerodynamics; kernel function; cylindrical function; lifting surface

\section{INTRODUCTION}

Investigations are in progress for the improvement of accuracy and efficiency of the load prediction methods for countless types of aerodynamic configurations ranging from simple two dimensional airfoils to complicated full scale aircrafts [1]. Since its derivation in 1940, Küssner's governing formulation is the origin of most aerodynamic load formulations for thin lifting surfaces [2,3]. The fundamental part in the Küssner integral equation is the so-called kernel function which relates aerodynamic pressure and normal wash velocity. Several forms of the kernel function have been proposed in the past, including the formulation of Watkins et al. [4], Laschka [5], Yates [6], Landahl [7], and 
Berman et al. [8]. The effect of acoustics in the integral equation is formulated by $\mathrm{Yu}$ et al. [9]. The widely accepted formulation of the kernel function is due to Landahl where the formula is used in aeroelastic analysis tool of MSC Nastran software. All of these formulations contain a hyper-geometric function of incomplete cylindrical function type whose solutions are not readily available in commercial software.

Most of the literatures use approximation methods to solve the incomplete cylindrical function [3, 8]. The first approximate method was adopted by Watkins et al. [10] which is used in unsteady aerodynamic doublet lattice method of Ref. 8. Laschka [11] presented both analytical and numerical solutions for the kernel function with three digit accuracy. Similar numerical approximation of series of fraction with constant numerators was offered by Dat and Malfois [12]. Least square technique is suggested by Desmarais $[13,14]$ in order to minimize the error in the approximation. Ueda [15] presented an expansion series to solve analytically the problem. However, the Ueda series requires a large number of steps for a large number of arguments of oscillating functions as shown in [2]. To increase the accuracy of the kernel function evaluation, an analytical separation of singular and regular functions occurring in the incomplete cylindrical function is proposed in [16] by modifying the expansion series. Another analytical solution is presented by Bismarck-Nasr [17] based on differential equation approach. [18] described possible extension of the kernel function formulation to transonic flow and separated flow. Epstein and Bliss [2] suggested an approximation to the incomplete cylindrical function by dividing the regions of integration into two parts which are near and far fields. Their work in Ref. 2 is presented for the planar lifting surfaces. Following the Epstein-Bliss approach, in the present work such approach is extended to non planar lifting surfaces and the accuracy is increased by adding more terms to the approximation function.

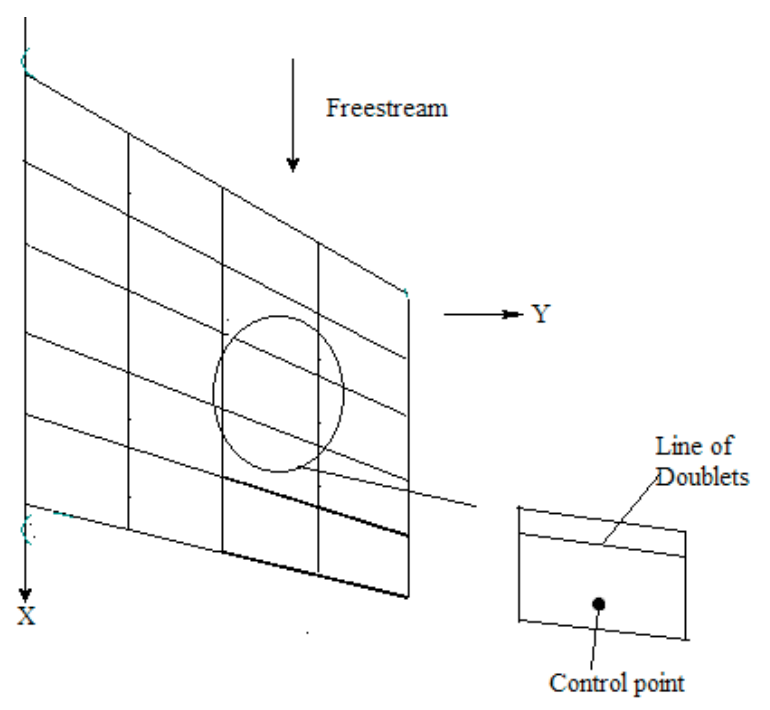

Fig. 1: Surface and Panel (box) geometry.

\section{GOVERNING EQUATION}

The Küssner integral equation relating the pressure and the normal wash distribution in the unsteady potential derivation is written as [3]: 


$$
\frac{w}{U}=\iint\left[\frac{\Delta p K(x, y, z, \xi, \eta, \zeta, k, M)}{8 \pi q r^{2}}\right] d \xi d \eta
$$

where $w$ is the normal wash velocity at the control point $(x, y, z)$ on the lifting surface as shown in Fig. 1, $U$ is the free stream velocity of the unperturbated flow assumed in the $x$ axis direction; and $\Delta p$ is the nonstationary aerodynamic pressure difference at point $(\xi, \eta, \zeta)$ along the line of doublets of each trapezoidal aerodynamic model box shown in Fig. 1. The free stream dynamic pressure is denoted by $q$ and is equal to $\rho U^{2} / 2$ where $\rho$ is the free stream air density. The kernel function of the integral $K$ is a function of relative position, the free stream Mach number $M$, and the reduced frequency $k$. The relative position between the control point and the doublet pressure location can be expressed as:

$$
\begin{aligned}
& x_{0}=x-\xi \\
& y_{0}=y-\eta \\
& z_{0}=z-\zeta
\end{aligned}
$$

and the reduced frequency $k$ is defined as

$k=\frac{\omega L}{U}$

where $L$ is the reference length.

\subsection{Planar Surfaces}

The kernel function $K$ given in Epstein[2] for planar lifting surface is written as

$$
K\left[x_{0}, y_{0}, k, M\right]=e^{-i k x_{0}} \frac{M e^{-i k X}}{R \sqrt{X^{2}+r^{2}}}+B(k, r, X)
$$

where $B$ is the incomplete cylindrical function formulated according to Landahl [7] and Ueda [15] as

$B(k, r, x)=\int_{-\infty}^{X} \frac{e^{i k v}}{\left(r^{2}+v^{2}\right)^{\frac{3}{2}}} d v=\frac{1}{r^{2}} \int_{-\frac{X}{r}}^{\infty} \frac{e^{i k r u}}{\left(1+u^{2}\right)^{\frac{3}{2}}} d u$

and the modified distance $r, R$ and $X$ are defined as

$$
\begin{aligned}
& r=\sqrt{(y-\eta)^{2}}=\left|y_{0}\right| \\
& R=\sqrt{x_{0}^{2}+\beta^{2} r^{2}} \\
& X=\frac{x_{0}-M R}{\beta^{2}} r^{2} \\
& \beta^{2}=1-M^{2}
\end{aligned}
$$

Separating the real and imaginary terms [2] from Eqn (3) yields

$$
B(k, r, X)=B_{r}+i B_{i}=\frac{1}{r^{2}} \int_{-\frac{X}{r}}^{\infty} \frac{\cos (k r u)}{\left(1+u^{2}\right)^{\frac{3}{2}}}+\frac{i}{r^{2}} \int_{-\frac{X}{r}}^{\infty} \frac{\sin (k r u)}{\left(1+u^{2}\right)^{\frac{3}{2}}}
$$


and integrating the equation by parts gives

$$
B(k, r, X)=\frac{1}{r^{2}}[\mathrm{~V}]_{-|X / r|}^{\infty}-k^{2} r^{2} \int_{-\frac{X}{r}}^{\infty} e^{i k r u} F(u) d u
$$

where the term $V$ represents the non-integral term

$$
V=e^{i k r u}\left[\frac{u}{\sqrt{1+u^{2}}}-1\right]-k r e^{-i k r u}\left[-u+\sqrt{1+u^{2}}\right]
$$

and the function $F(u)$ is defined by

$F(u)=-u+\sqrt{1+u^{2}}$

In the present work, a simple curve fitting technique is utilized to approximate $F(u)$ as follows:

$$
F(u) \cong f(u)= \begin{cases}f_{a}(u) & \text { for } u \leq 1.5 \\ f_{b}(u) & \text { for } u \geq 1.5\end{cases}
$$

where $f_{a}(\mathrm{u})$ and $f_{b}(\mathrm{u})$ are defined as

$$
\begin{aligned}
f_{a}(u) & =\sum_{i=0}^{7} a_{i} u^{i} \\
f_{b}(u) & =\sum_{i=1}^{6} b_{i} u^{-i}
\end{aligned}
$$

and the coefficients $a_{i}$ and $b_{i}$ are defined in Table 1 .

Table 1: Coefficients $a_{i}$ and $b_{i}$ of Eqn (8) and (9).

\begin{tabular}{ccc}
\hline $\mathbf{i}$ & $\boldsymbol{a}_{\boldsymbol{i}}$ & $\boldsymbol{b}_{\boldsymbol{i}}$ \\
\hline $\mathbf{0}$ & 0.99999933 & -- \\
$\mathbf{1}$ & -0.99968242 & 0.49998705 \\
$\mathbf{2}$ & 0.49488907 & 0.00017800315 \\
$\mathbf{3}$ & 0.0303999182 & -0.12594842 \\
$\mathbf{4}$ & -0.21413252 & 0.00099707005 \\
$\mathbf{5}$ & 0.13894299 & 0.071073596 \\
$\mathbf{6}$ & -0.041028643 & -0.032656364 \\
$\mathbf{7}$ & 0.0048280266 & -- \\
\hline
\end{tabular}

The accuracy of the present approximation is demonstrated in Fig. 2 and Fig. 3. In Fig. 2, the plot of $f(u)$ resembles the target function $F(u)$. The plot of the error representing the difference between $F(u)$ and $f(u)$ is presented in Fig. 3. The maximum error for the present approximation is $3.5 \times 10^{-6}$ at $u=1.4$. Figure 3 also presents the plot of the error if the approximation of Epstein-Bliss [2] is used. The maximum error of their error is 0.015 which occurs at $u=0.5$. Therefore, the present approximation provides much better accuracy compare to the approximation of Ref. 2. Note that the plot for the Epstein-Bliss 
approximation in Fig. 3 is multiplied by $10^{-3}$ whereas for the present approach is multiplied by $10^{-6}$ in order to show the sensitivity changes in the error.

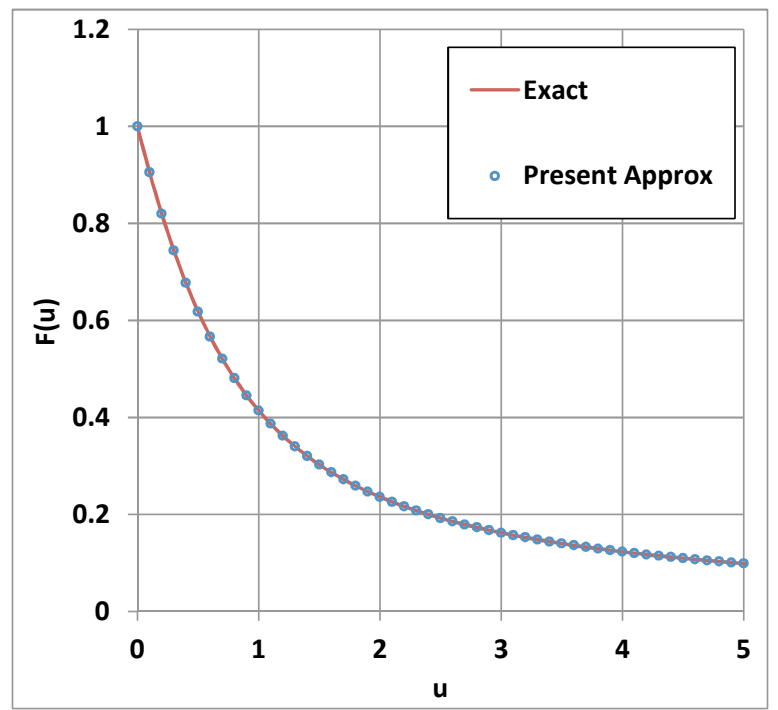

Fig. 2: Comparison between the present approach $f(u)$ and the target function $F(u)$.

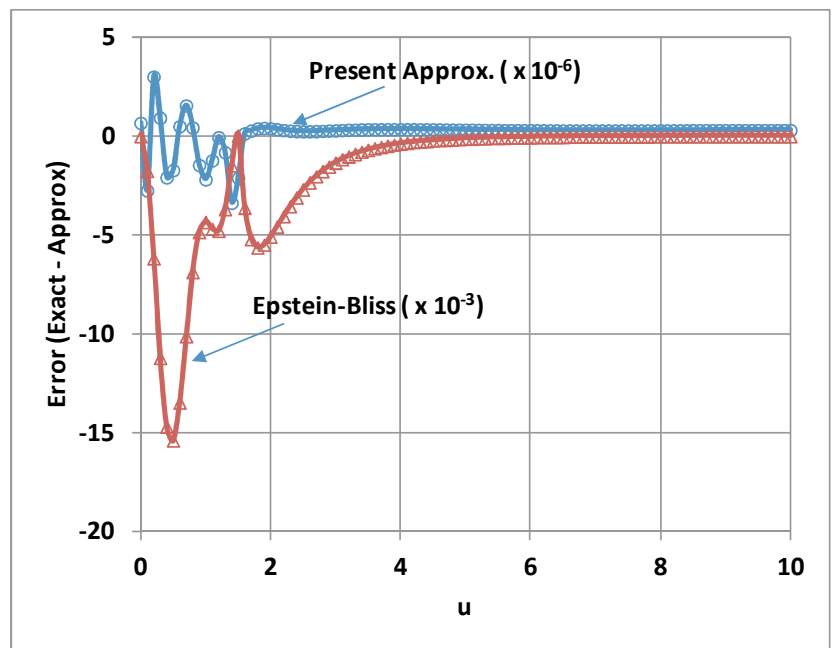

Fig. 3: Comparison between the error of the present approach $f(u)$ and the Epstein-Biss approach with respect to the target function.

Figure 4 shows comparison of $B_{r}(k, r, X)$ between the exact analytical solution of series expansion $[14,15]$ and the present approximation. Figure 5 shows comparison of $B_{i}(k, r, X)$ between the exact and the present approximation. To show the accuracy of the present approximation, the error or the difference between the analytical solution and the present approximation is plotted in Figs. 6 and 7 for $B_{r}$ and $B_{i}$ respectively. Both figures also present the error for $B_{r}$ and $B_{i}$ calculated using Epstein-Bliss approximation which demonstrates the improvement of the present approximation. Figure 6 shows that the maximum error of the Epstein-Bliss approximation for $B_{r}$ is 0.0127 whereas the present approximation gives the maximum error of 0.00047 . In Fig. 7, the maximum difference for $B_{i}$ using the Epstein-Bliss approximation is 0.0094 . But the new approximation plot shows the accuracy of 0.0000667 which increases the applicability of the new approximation to a good extent in solving the incomplete cylindrical function in the kernel function. 


\subsection{Nonplanar Surfaces}

Rodemich [19] derived an expression in 1965 for the kernel function of nonplanar lifting surfaces as follow:

$$
K=e^{-\left(\frac{i \omega x_{0}}{U}\right)}\left(K_{1} T_{1}+K_{2} T_{2}\right) / r_{1}^{2}
$$

where

$$
\begin{aligned}
& T_{1}=\cos \left(\gamma_{s}-\gamma_{r}\right) \\
& T_{2}=\frac{1}{r_{1}{ }^{2}}\left(z_{0} \cos \gamma_{s}-y_{0} \sin \gamma_{r}\right)\left(z_{0} \cos \gamma_{r}-y_{0} \sin \gamma_{s}\right) \\
& K_{1}=I_{1}+\left[\frac{M r_{1}}{R}\right] \frac{e^{-i k_{1} u_{1}}}{\left(1+u_{1}^{2}\right)^{\frac{1}{2}}} \\
& K_{2}=-3 I_{2}-\frac{e^{-i k_{1} u_{1}}}{\left(1+u_{1}^{2}\right)^{\frac{1}{2}}}\left[\frac{i k_{1} M^{2} r_{1}^{2}}{R^{2}}-\frac{M r_{1}}{R}\left\{\frac{\left(1+u_{1}^{2}\right) \beta^{2} r_{1}^{2}}{R^{2}}+2+\frac{M r_{1} u_{1}}{R}\right\}\right]
\end{aligned}
$$

where the incomplete cylindrical functions are given as

$$
\begin{aligned}
& I_{1}=\int_{u_{1}}^{\infty} \frac{e^{-i k_{1} u}}{\left(1+u_{1}^{2}\right)^{\frac{3}{2}}} d u=r_{1}^{2} B_{1} \\
& I_{2}=\int_{u_{1}}^{\infty} \frac{e^{-i k_{1} u}}{\left(1+u_{1}^{2}\right)^{\frac{5}{2}}} d u=r_{1}^{4} B_{2}
\end{aligned}
$$

where

$$
\begin{aligned}
& r_{1}=\left(y_{0}^{2}+z_{0}^{2}\right)^{1 / 2} \\
& u_{1}=\frac{M R-x_{0}}{\beta^{2} r_{1}} \\
& k_{1}=\frac{\omega r_{1}}{U}
\end{aligned}
$$

The incomplete cylindrical function for nonplanar surfaces $I_{2}$ can be further separated into real and the imaginary parts as follows

$$
I_{2}=I_{2 r}+I_{2 i}=\int_{u_{1}}^{\infty} \frac{\cos \left(k_{1} u\right)}{\left(1+u_{1}^{2}\right)^{\frac{5}{2}}} d u+i \int_{u_{1}}^{\infty} \frac{\sin \left(k_{1} u\right)}{\left(1+u_{1}^{2}\right)^{\frac{5}{2}}} d u
$$

The above given approximations in Eqn (8) and Eqn (9) could be utilized for nonplanar conditions. The solution will be extended towards the derivation of the function $F(u)$.

Figure 8 shows comparison of $B_{r}$ with the exact analytical solution of the series expansion method [15]. The accuracy is quite considerable where it is shown in the Fig. 9 which shows the maximum error of $1.15 \times 10^{-6}$. In Fig. 10 the comparison of the $\mathrm{Bi}$ is compared with that of the expansion series method and the accuracy can be read in Fig. 11 which shows the maximum differences of $9 \times 10^{-6}$ for the range until $X=10$. 


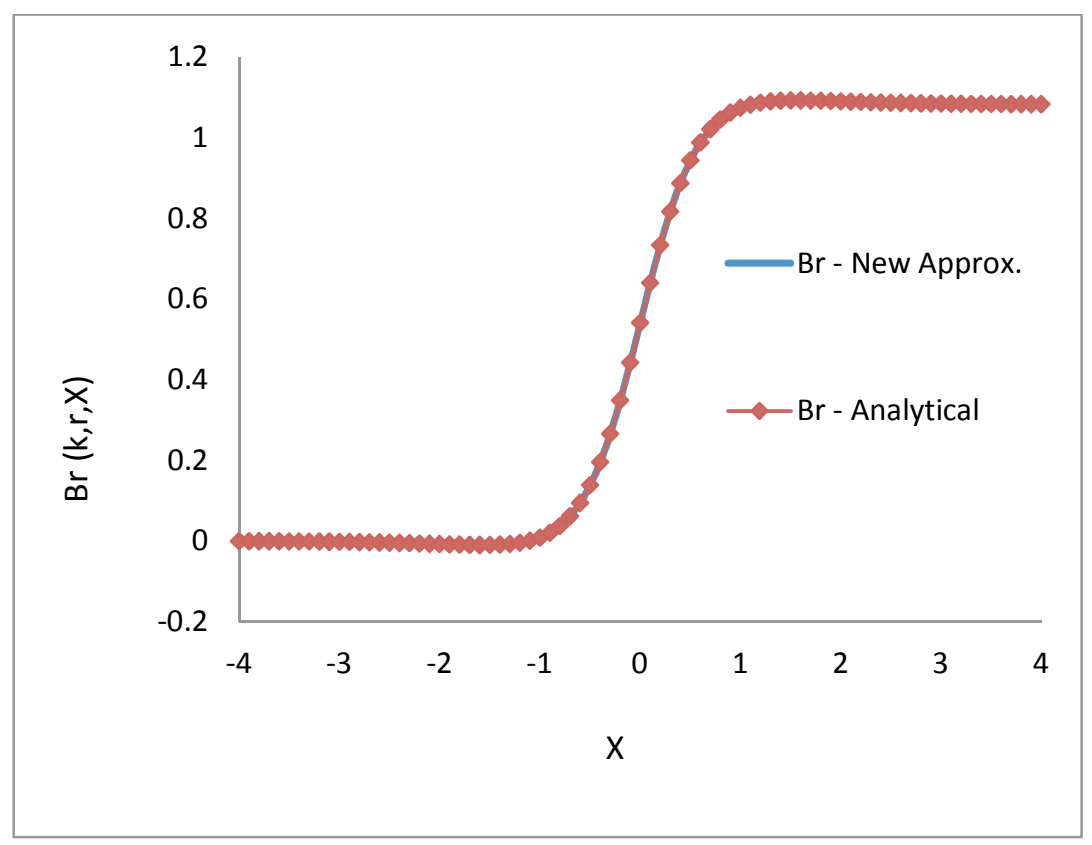

Fig. 8: Comparison of $B_{r}$ (Nonplanar) between the present method and the series expansion method for $k=1.0$ and $r=1.0$.

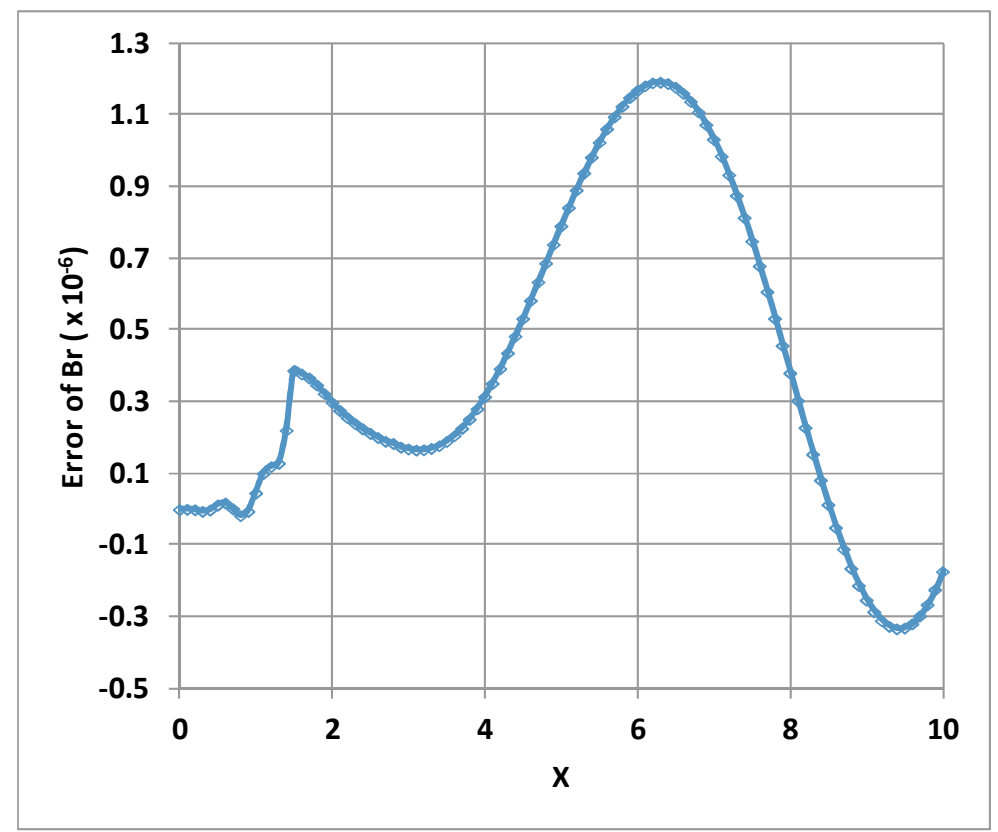

Fig. 9: Difference of $B_{r}$ (Nonplanar) with the analytical solution for $k=1$ and $r=1$. 


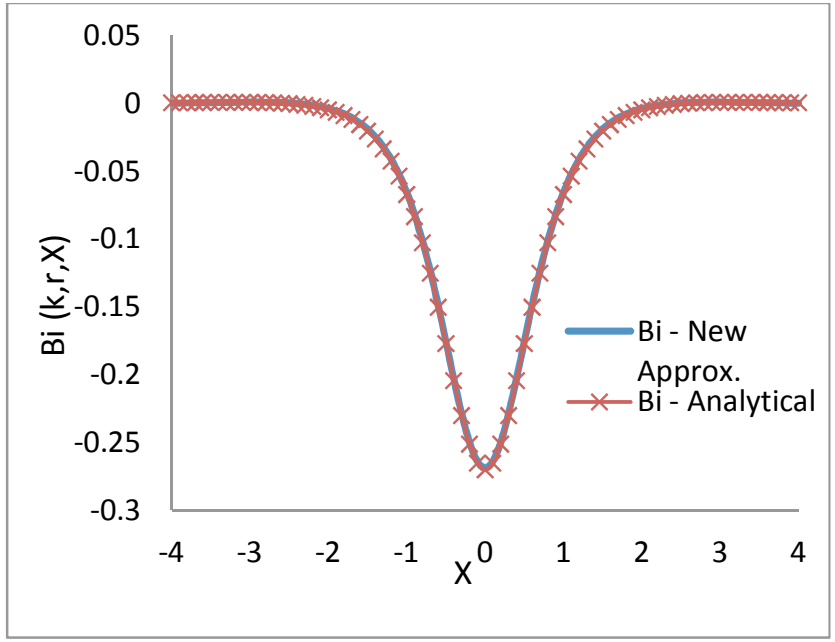

Fig. 10: Comparison of $B_{i}$ (Nonplanar) between the present method and the series expansion method for $k=1.0$ and $r=1.0$.

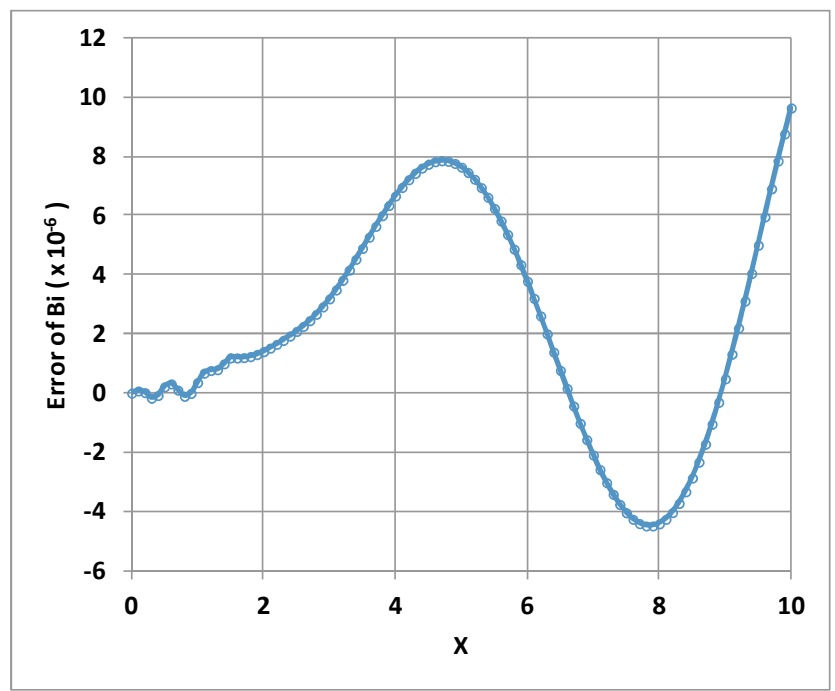

Fig. 11: Difference of $B_{i}$ (Nonplanar) with the analytical solution for $k=1$ and $r=1$.

\section{CONCLUSION}

In the present method the solution to the incomplete cylindrical function is derived to a certain extent and the non-oscillatory part of the integrand is approximated using a simple curve fitting technique. The accuracy is appreciable with the comparison of analytical series expansion method. The applicability of the presented approximation to planar and non-planar configurations is augmented due to its plainness and the precision.

\section{ACKNOWLEDGEMENT}

The authors would like to acknowledge the financial support rendered by the Ministry of Education (MOE) Malaysia, under an FRGS grant (13-020-0261). 


\section{REFERENCES}

[1] Ahmed, L., Sulaeman, E. "Alternate Approximate function for Kernel Function of Planar Oscillation Lifting Surfaces." In Selected Topics in Aerospace Engineering, Kuala Lumpur: IIUM Press, (2011).

[2] Epstein, R.J., Bliss, D.B. "Alternative Solution of the Kernel Function in Subsonic Unsteady Lifting Surface Theory.” AIAA Journal, 33 (1995):2228-30.

[3] Sulaeman, E. Formulation of Kernel Function for Aerodynamic Loading on Air Vehicle. In Selected Topics in Aerospace Engineering, Kuala Lumpur: IIUM Press. (2011)

[4] Watkins, C.E., Runyan, H.L., Woolston, D.S. On the Kernel Function of the Integral Equation Relating the Lift and Downwash Distribution of Oscillating Finite Wings in Subsonic Flow. .NACA-1234. National Aeronautics and Space Administration Hampton Va Langley Research Center, 1955.

[5] Laschka, B"Das Potential und das Geschwindigkeitsfeld der Harmonisch schwin-genden tragenden Flache bei Unterschallanstromung." Z. Angew. Math. Mech. 43(1963):325-333.

[6] Yates, E.C. Jr ("A Kernel Function for Nonplanar Oscillating Surfaces in Subsonic Flow. AIAA Journal, 5(1966):1486-88.

[7] Landahl, M.T"'Kernel Function for Nonplanar Oscillating Surfaces in a Subsonic Flow." AIAA Journal, 4(1967):1045-46.

[8] Berman, H.J., Shyprykevich, P., Smedfjeld, J.B. "Subsonic Nonplanar Kernel Function for Surfaces Inclined to the Freestream.” Journal of Aircraft 7(1970):188-190.

[9] Yu KH, Djojodihardjo H, Kadarman AK. "Acoustic Effects on Binary Aeroleasticity Model.” IIUM Engineering Journal, 12.2(2011):123-129.

[10] Watkins, C.E., Woolston, D.S., Cunningham, H.J. "A systematic Procedure for determining Aerodynamics Forces on Oscillating or Steady Finite Wings at Subsonic speed". In ." NASA 19980227841 (1959).

[11] Laschka, B. Zur Theorie der Harmonisch Schwingenden Tragenden Flache bei Unterschallanstromung. Z. Flugwissenschaften, 11.7(1963):265-292.

[12] Dat, R., Malfois, J.P. "Sur le Calcul du Noyau de l'Equation Integrale de la Surface Postante en Ecoulement Subsonique Instationnaire." La Recherche Aerospatiale, 5(1970):251-259.

[13] Desmarais, R.N. "Accurate Numerical Evaluation of Modified Struve Functions Occurring in Unsteady Aerodynamics." Journal of Aircraft, 16.7(1979):441-47.

[14] Albano, E., Rodden, W.P.) "A Doublet Lattice Method for Calculating Lift Distribution on Oscillation Surfaces in Subsonic Flow." AIAA Journal, 7.2(1969):279-85.

[15] Ueda, T. "Expansion Series of Integral Functions in Unsteady Aerodynamics." Journal of Aircraft, 19(1982):345-47.

[16] Brendel, M., Sulaeman, E. "Improved Doublet Lattice Formulation for Calculating Aerodynamic Loads on Lifting Surface in Unsteady Subsonic Flow.” AIAA Paper 19941890, 12th AIAA Applied Aerodynamic Conference, Colorado. (1994)

[17] Bismarck-Nasr, M.N. "Kernel Function Occuring in Subsonic Unsteady Potential Flow." AIAA Journal, 29(1991):878-79.

[18] Sulaeman, E., Djojodihardjo, H. "An Expansion Series for Solving Improper Cylindrical Functions Occuring in Subsonic, Supersonic and Transonic Kernel Formulations." In Contemporary Research in Engineering Sciences, Springer Verlag, Berlin. (1995).

[19] Vivian, H.T., Andrew, L.V. "Unsteady aerodynamic for advanced configurations." Part IApplications of the subsonic kernel function to nonplanar lifting surfaces, RDL-TDR-152, Airforce Flight Dynamics Lab, Dayton, OH. (1965). 